\title{
An Unusual Case of Bull Gore Injury to the Neck Presenting with Internal Jugular Vein Thrombosis and Retropharyngeal Emphysema
}

\author{
R Anil Kumar, J Niveditha, M Mahesh Babu
}

\begin{abstract}
Injuries to the head and neck region are less common than genitourinary, abdominal, inguinal region but are more severe and more likely to cause death. ${ }^{1} \mathrm{~A} 22$-year-old patient presented with dysphagia and swelling in left lower part of the neck secondary to bull gore injury. The injury had caused a retropharyngeal hematoma, emphysema of the neck along with internal jugular vein thrombosis and with air in the lumen of the vein. Pulmonary embolism resulted in sudden death of the patient.
\end{abstract}

Keywords: Bull gore injury, Internal jugular vein thrombosis, Retropharyngeal hematoma, Retropharyngeal emphysema, Pulmonary embolism.

How to cite this article: Kumar R A, Niveditha J , Babu MM. An Unusual Case of Bull Gore Injury to the Neck Presenting with Internal J ugular Vein Thrombosis and Retropharyngeal Emphysema. Int J Phonosurg Laryngol 2013;3(1):18-20.

\section{Source of support Nil}

\section{Conflict of interest: None}

\section{INTRODUCTION}

Bull gore injury may be trivial or fatal depending on site and extent of injury. Trauma to the neck may vary from a simple laceration to carotid artery rupture. ${ }^{2} \mathrm{~T}$ he present case is extremely unusual, i.e. retropharyngeal hematoma, emphysema of the neck along with internal jugular vein (IJV) thrombosis and with air in the lumen of the vein following bull gore injury, and has not been reported before.

\section{CASE REPORT}

A 22-year-old deaf-mute male was brought to the outpatient department with a history of difficulty in swallowing and swelling in the left lower part of the neck since 2 days.

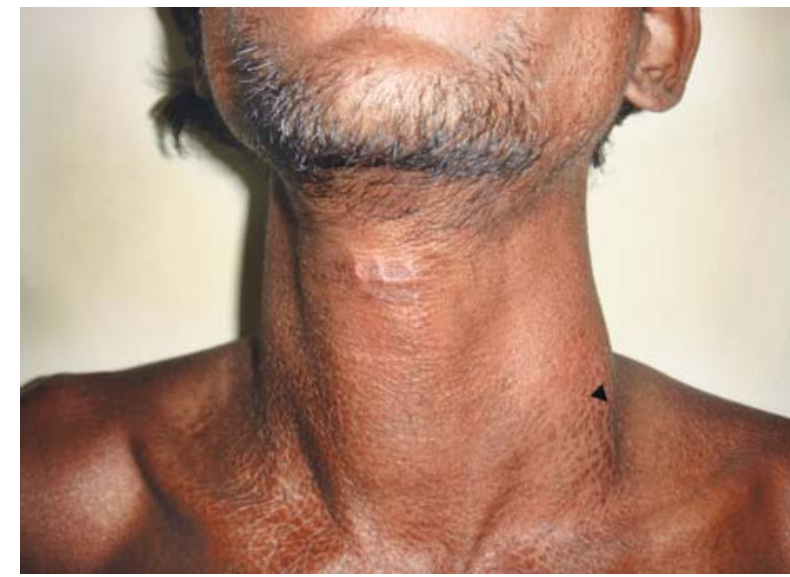

Fig. 1: Swelling in the left lower part of the neck (arrowhead)

Patient sustained a bull gore injury to the upper part of the neck, 1 week back following which patient developed these symptoms. There was no history of fever or difficulty in breathing.

On examination there was healed wound at the level of hyoid bone about $2 \times 0.5 \mathrm{~cm}$ indicating the injury. Smooth diffuse swelling was present in the left lower part of the neck, in the posterior triangle. The swelling was nontender, firm in consistency with no local rise of temperature, no induration and was nonpulsatile (Fig. 1).

Computed tomographic (CT) scan revealed a large welldefined fluid attenuating collection with multiple air foci within the retropharyngeal space. Posterolaterally, the collection was seen eroding into the posterior wall of left IJV over a length of $4 \mathrm{~cm}$ causing thrombosis with air foci within the lumen of IJV . F ew small pockets of collection in the posterior triangle showed peripheral enhancement, suggestive of secondary infection (Figs 2A to C).
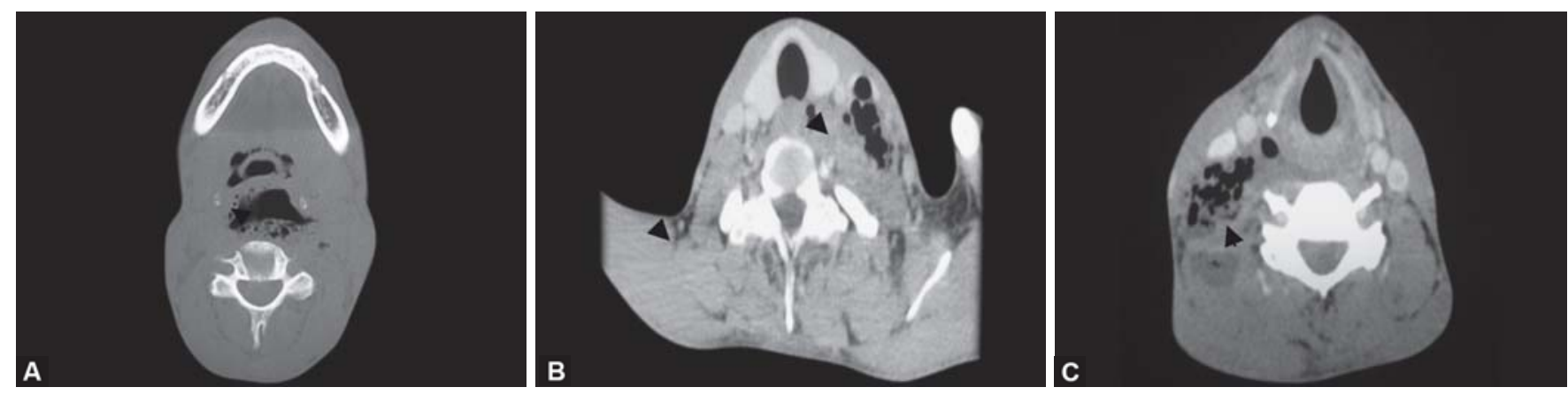

Figs 2A to C: Multiple air foci within the retropharyngeal space. Posterolaterally, the collection is seen eroding into the posterior wall of left IJV over a length of $4 \mathrm{~cm}$ causing thrombosis with air foci within the lumen of IJV (arrowhead) 

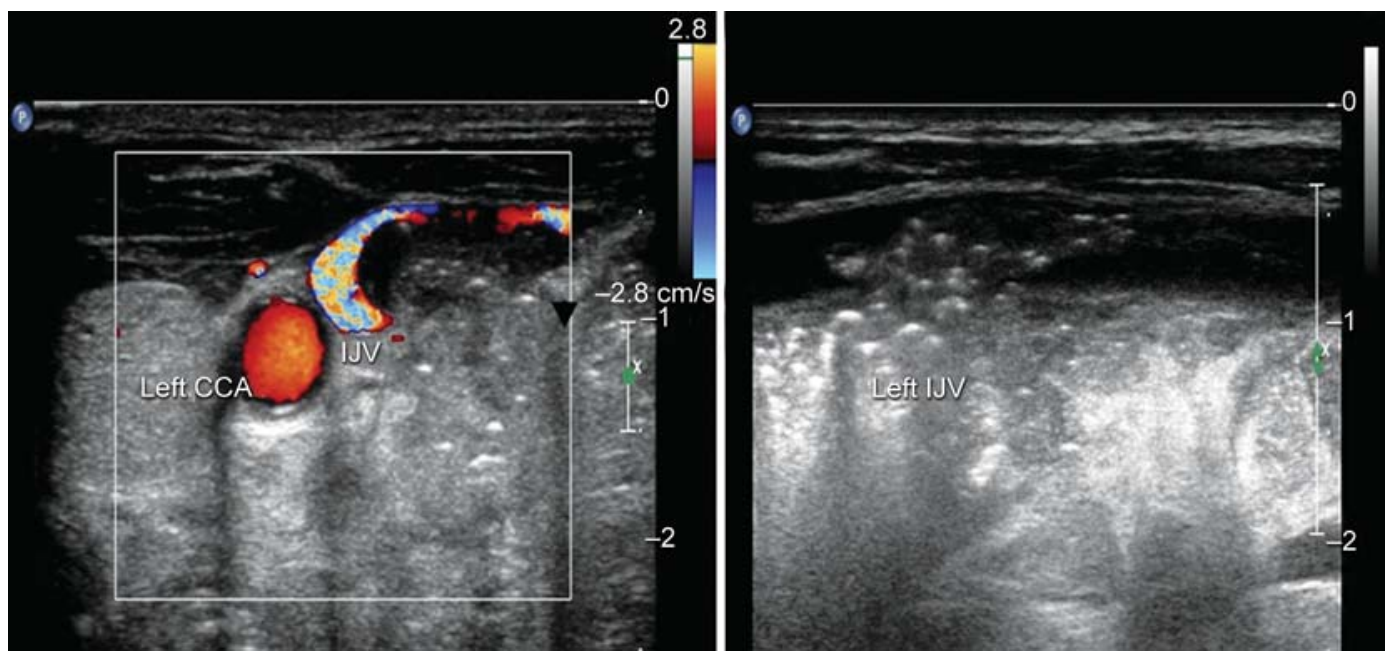

Fig. 3: Thrombus and multiple air foci inside IJV

Ultrasound confirmed the jugular vein thrombosis and air foci within (Fig. 3).

Surgical evaluation of the hematoma was not required as the patient was stable, as uncomplicated cases of IJV thrombosis sel dom require surgical intervention. A bout $5 \%$ of IJ V thrombosis developed pulmonary embolism. ${ }^{11}$ Since, the patient's vital signs were stable and he did not show any progressive signs and symptoms of retropharyngeal hematoma or IJV thrombosis, patient was managed conservatively. The very next day patient devel oped sudden onset of breathing difficulty, pink frothy sputum, collapsed and died.

\section{DISCUSSION}

\section{Biomechanics of Bull Gore Injury}

Primary Gore Injury

Knowledge of the mechanism of injury by bull horns is important to appreciate the complexity of these wounds. As the bull charges and accelerates toward its subject, it initially lowers its head by neck flexion right before engaging; it then extends its neck powerfully, driving one or both horns into the subject. The mass of the animal combined with its acceleration result in tremendous amounts of force being applied at the point of entry of the sharp horn. The bull follows through with its neck extension while engaged with the subject with its horn(s). A s the subject is raised violently off the ground, the bull's head stereotypically tosses its head in a circular movement. The horn thereby acts as a fixed vertical axis, while the powerful head movement turns the victim, with all his weight on it, about the horn(s), causing further shearing. ${ }^{10}$ This combined motion results in massive deep tissue damage.

\section{Secondary Bull Injury}

Although the primary bull-goring injury results in femoral vascular, inguinal, abdominal and genitourinary injury, secondary injury may result in a head and neck injury by direct head and neck goring.

If a person attempts to stand up again after being throw $\mathrm{n}$ by a goring and the bull maintains its attention on him as a target and charges again, there is the potential for very serious secondary patterns of goring injury that strike the head and neck directly. Because the subject is typically kneeling down, the primary goring site is no longer the midthigh to mid-abdominal region and is now the head and neck region.

Overall, the reported rates of injury to the head and neck in a bull-goring encounter vary from 3.1 to $19 \% .^{3-5}$ In a study focusing entirely on goring injuries to the face and neck, three patients had cervical injuries which were of neurosurgical interest, including two carotid transections and a cervical fracture and one of the facial injuries involved transection of the facial nerve. ${ }^{6}$ Although they are less common than abdominal, inguinal, and lower extremity injuries, head and neck lesions are generally most severe including death secondary to intracerebral hemorrhage. Direct goring of the neck may also result in laceration of the carotid artery or IJ V.

A high index of suspicion is needed to diagnose a retropharyngeal hematoma. The onset is usually acute but can also be insidious and patient may present several days after the initial insult. They may presents with sore throat, difficulty in swallowing, odynophagia, trismus, torticollis. Not all retropharyngeal hematomas warrant surgical intervention. A patient with nonexpanding hematoma should be observed in the hospital and the hematoma should be 
regularly assessed by clinical evaluation and flexible nasoendoscopy and radiological study. Surgical evacuation of the hematoma is necessary when the patient has a lifethreatening airway obstruction, rapidly expanding hematoma or inability to achieve ventilation through tracheostomy. ${ }^{6}$ Our patient did not undergo surgical intervention as he did not show any respiratory distress and his vitals signs were stable.

A ir embolism is a serious complication of a lacerated wall of IJV. ${ }^{7}$ Since, the wall of this large vein contains very little smooth muscle, its injury is not followed by contraction and retraction. Moreover, the outer coat of the vein is attached to fascia of carotid sheath which hinders the collapse of the vein. M ortality and morbidity of venous air emboli are related to the volume of gas entrapment, rate of accumulation and patient position at the time of the event. ${ }^{8}$

The risk of pulmonary embolism following IJV thrombosis is truly unknown. The most commonly quoted rate of pulmonary embolism occurring in the setting of IJ V thrombosis is $5 \% .{ }^{9} \mathrm{~A}$ recent retrospective study demonstrated pulmonary embolism rates of 0.5 and $2.4 \%$ for isolated IJV thrombosis and combined subclavian/axillary vein and IJV thrombosis respectively.

Uncomplicated cases IJV thrombosis seldom require surgical intervention. ${ }^{11}$ However, cases associated with deep neck infections require drainage of any fluid collections and debridement of all infected tissue. Role of anticoagulation is controversial.

\section{CONCLUSION}

Injuries to the head and neck, although less common, are severe and more likely to result in death. ${ }^{12,13}$

Bull gore injury to the neck can present with unusual symptoms like dysphagia and swelling in the neck with underlying life-threatening complications like a retropharyngeal hematoma, IJV thrombosis and air embolism as described in the above case report, but uncomplicated cases seldom require surgical intervention.

\section{REFERENCES}

1. Onwudike M, Olaloye OA, Oni OO. Teaching hospital perspective of the quality of trauma care in Lagos, Nigeria. W orld J Surg 2001;25:112-15.
2. Henderson KI, Coats TJ, Hassan TB, Brohi K. A udit of time to emergency trauma laparotomy. B r J Surg 2000;87:472-76.

3. Stuart G, Y elland JD, Balderson G. 3000 head injuries: A prospective study of patients admitted to B risbane neurosurgical units. J Clin N eurosci 1998;5:402-05.

4. Markogiannakis $H$, Sanidas $E, M$ essaris $E$, K outentakis $D$, A Ipantaki K, K afetzakis A, et al. M otor vehicle trauma: A nalysis of injury profiles by road-user category. Emerg M ed J 2006:23:27-31.

5. Chiang M F, Chiu WT, Chao HJ, Chen WL, Chu SF, Chen SJ, et al. Head injuries in adolescents in Taiwan: A comparison between urban and rural groups. Surg Neurol 2006;66 (Suppl 2):S14-19.

6. Cleiman P, Nemeth J, V etere P. A significant cervical spine fracture: Think of the airway. J Emerg M ed 2009 J an 5.

7. Ho AM, Ling E. Systemic air embolism after lung trauma. A nesthesiology $1999 \mathrm{Feb} ; 90(2): 564-75$.

8. Platz $\mathrm{E}$. Tangential gunshot wound to the chest causing venous air embolism: A case report and review. J Emerg M ed 2011 Aug; 41(2):e25-29.

9. A scher E, Salles-C unha S, Hingorani A . M orbidity and mortality associated with internal jugular vein thromboses. V asc Endovascular Surg 2005 J ul-A ug;39(4):335-39.

10. Crespo Escudero J L, A renaz Búa J, Luaces Rey $R$, et al. $M$ axillofacial injury by bull goring: Literature review and case report. Rev Esp Cirug Oral M axilofac 2008;30(5):353-62.

11. Tovi F, Fliss DM, Gatot A, Hertzanu Y. Septic jugular thrombosis with abscess formation. A nn O tol Rhinol Laryngol 1991 A ug;100(8):682-84.

12. E mejuluJK. E pidemiological patterns of head injury in a new ly established neurosurgical service: O ne-year prospective study. Afr J Med Sci 2008;37:383-88.

13. Rani M, Sharma RA, Dikshit PC. Injuries by bull horns: Patterns and prevention protocols. A nil A ggrawal's Internet Forensic Med Toxicol 2010;11(1):6.

\section{ABOUT THE AUTHORS}

\section{R Anil Kumar (Corresponding Author)}

Assistant Professor, D epartment of ENT, V ictoria H ospital, B angal ore M edical College and R esearch Institute, B engaluru, K arnataka, India e-mail: dranil24@yahoo.com

\section{J Niveditha}

Resident, Department of ENT, V ictoria H ospital, B angal ore M edical College and Research Institute, B engaluru, K arnataka, India

\section{Mahesh Babu}

Professor, D epartment of ENT, V ictoria H ospital, Bangal ore M edical College and Research Institute, B engal uru, K arnataka, India 